\title{
Hypospadias: One Defect, Multiple Causes, Acting Through Shared Pathways
}

\author{
Kristin Palmsten • Christina D. Chambers
}

Published online: 6 January 2015

(C) Springer International Publishing AG 2015

\begin{abstract}
Hypospadias is one of the most common birth defects among males. Although the birth prevalence of hypospadias has been reported as increasing in some geographic regions, inconsistencies in ascertainment of mild cases and variability in reporting standards are likely contributing to these apparent trends. While hypospadias is highly heritable, there is limited knowledge about the specific genetic and epigenetic factors that play a role in its etiology. Risk factors for hypospadias include family history, older maternal age, nulliparity, high maternal prepregnancy body mass index, hypertension or preeclampsia, multiple gestations, reduced birth weight, and small for gestational age. Of the various prenatal exposures to medications that have been studied, the strongest evidence supports valproic acid as a contributor to hypospadias. Studies evaluating the impact of assisted reproductive technologies (ART) on hypospadias are inconclusive because of potential confounding by subfertility. Many causes of hypospadias may act through a few shared pathways, such as placental dysfunction.
\end{abstract}

Keywords Assisted reproductive technology - Birth defects . Congenital malformations · Diethylstilbestrol · Endocrine disruptors $\cdot$ Epigenetics $\cdot$ Genetics $\cdot$ Hypospadias ·

This article is part of the Topical Collection on Reproductive and Perinatal Epidemiology

\footnotetext{
K. Palmsten $(\bowtie) \cdot$ C. D. Chambers

Department of Pediatrics, University of California, San Diego, 9500

Gilman Drive \#0828, La Jolla, CA 92093-0828, USA

e-mail: kpalmsten@ucsd.edu

C. D. Chambers

e-mail: chchambers@ucsd.edu

C. D. Chambers

Department of Family Medicine and Public Health, University of

California, San Diego, 9500 Gilman Drive \#0828, La Jolla,

CA 92093-0828, USA
}

Intracytoplasmic sperm injection · In vitro fertilization · Medications · Pharmacoepidemiology · Pregnancy · Pesticides $\cdot$ Risk factors $\cdot$ Valproic acid

\section{Introduction}

Hypospadias is a congenital malformation of the penis in which the urethral opening or meatus is located on the ventral side of the penis, scrotum, or perineum [1]. This malformation results from abnormal fusion of the urethral folds during organogenesis [1]. Male sexual differentiation is driven by androgens derived from the fetal testis, and deficient androgen action between gestational weeks 8-14 is believed to induce hypospadias [2]. Traditionally, hypospadias has been classified according to the location of the urethral meatus [3]. Cases with the meatus at or distal to the coronal sulcus are considered to be mild; cases with the meatus on the penile shaft are classified as moderate; and cases with the meatus in the penoscrotal or perineal area are considered severe [4]. Although several other nomenclature systems are employed to describe the continuum of hypospadias, for the purposes of this paper, we will use the terms mild, moderate, and severe (Fig. 1).

Although hypospadias is one feature of many malformation syndromes[5], approximately $80 \%$ of cases are isolated, i.e., infants are not also affected by other non-genital congenital anomalies [6]. The majority (approximately $70 \%$ ) of cases of hypospadias are classified as mild [6]. The proportion of cases that undergo surgery varies by geographic region, suggesting that parental preference and/or local practices may play a role in the decision to repair cases that are on the milder end of the spectrum [6]. The incidence of surgical complications among those that are repaired is highest for severe cases; reoperation occurs in approximately $20-40 \%$ of surgically treated severe cases $[7,8]$. 


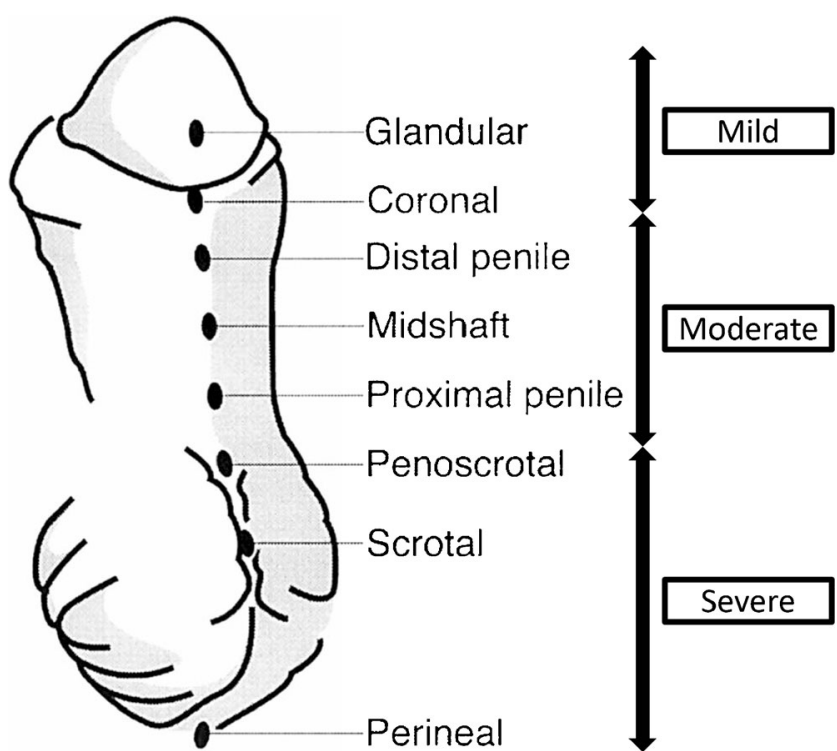

Fig. 1 Hypospadias classifications. Figure adapted from Pierik FH, Burdorf A, Nijman, JM, de Muinck Keizer-Schrama SM, Juttmann RE, Weber RF. A high hypospadias rate in The Netherlands. Hum Reprod. 2002;17(4):1112-1115. By permission of The European Society of Human Reproduction and Embryology [107]

The underlying causes of hypospadias are believed to be multifactorial with non-genetic factors interacting with epigenetic and genetic susceptibilities during the critical window of development between 8-14 weeks' gestation. When risk factors for hypospadias are examined by subtype, there is lack of consensus on whether hypospadias is one defect with varying severity, or whether there could be differing underlying etiologies for each subtype $[9,10,11 \bullet \cdot$. This brief review provides an update on variations in estimates of the birth prevalence of hypospadias, recent studies of genetic and epigenetic factors potentially involved in the etiology of the defect, and maternal and pregnancy risk factors for hypospadias, with a focus on the potential contributions of maternal medication use during pregnancy and assisted reproductive technologies (ART). The methodological challenges arising in conducting observational research regarding hypospadias are highlighted. Emphasis in this review is on the epidemiology of isolated hypospadias, as many of the available studies are either restricted to isolated cases or do not distinguish between isolated and non-isolated hypospadias.

\section{Birth Prevalence}

Hypospadias is one of the most common birth defects among males, although there are geographic and temporal variations in the reported prevalence [12-14]. In the United States, hypospadias occurs in 3 to 6 per 1000 male births [15-17]. Paulozzi et al. described a near doubling in the prevalence of hypospadias in live births between 1968-1993 within the Metropolitan Atlanta Congenital Defects Program [12]. A study from China reported that the prevalence of hypospadias was 0.76 for isolated and 0.14 for non-isolated cases per 1000 male births between 1996-2008 and that there was a $7.4 \%$ annual increase in hypospadias prevalence [13]. The most recent data from EUROCAT, a surveillance network of population-based congenital anomaly registries in Europe, indicated that between 1999-2008, the prevalence of hypospadias was approximately 3 per 1000 male births, and that there was a $1.8 \%$ increase in prevalence every two years [14].

These trends have raised interest in the possible influence of environmental factors that could have contributed to increased rates of hypospadias. However, it is controversial as to whether there has been a true increase in hypospadias rates over time in the United States or elsewhere [18]. Data from California between 1984-1997 indicated that the prevalence of hypospadias did not increase over that period, regardless of severity phenotype [15]. Subsequent reports from Washington (1987-2002) and New York (1992-2005) also found no evidence of an upward trend [16,17].

It is possible that the prevalence of hypospadias has increased in some populations but not others. Alternatively, variations in the reported birth prevalence could reflect differences in methods used across various malformation registries, e.g., inclusion vs. exclusion of stillbirths, and inclusion vs. exclusion of cases that do not undergo corrective surgery [6, 19-21]. At the clinical level, inconsistencies in diagnosis, surgical practice, and reporting for milder forms of hypospadias have likely contributed to variations in prevalence [6, 19-21]. Authors have cautioned against cross-country comparisons because of these factors, and temporal trends should be interpreted in light of these caveats as well [20, 21]. EUROCAT has provided an illustration of the challenges of tracking hypospadias prevalence over time. Prior to 2005, isolated cases of mild hypospadias were excluded from the EUROCAT Central Registry, [22] although these exclusions were not implemented uniformly by member registries [6]. However, since 2005, all hypospadias cases, regardless of severity, are eligible for registration in EUROCAT. The impact of this administrative change, and the lack of uniformity in how exclusions were applied prior to 2005, on temporal trends of hypospadias prevalence is being investigated [14].

\section{Genetics and Epigenetics}

Family aggregation of hypospadias is evident. As reported from Danish registers, having an affected twin was associated with a 50.8-fold (95\% confidence interval (CI): 34.2-75.5) increased risk for hypospadias; having an affected male sibling was associated with a 13.4-fold (95 \% CI: 11.0-16.4) increased risk; and having an affected father was associated with a 10.4-fold (95\% CI: 7.5-14.3) increased risk; the comparison groups were comprised of corresponding family 
members who were unaffected [23]. These associations were weaker for more distant relatives and heritability was estimated at $77 \%$ (95 \% CI: 57-90\%). Family history of hypospadias is more strongly associated with mild and moderate hypospadias than with severe forms, although estimates are imprecise $[9,10,11 \bullet \cdot$.

Evidence supports the interaction of multiple genetic and environmental factors as the cause of most cases of hypospadias, as opposed to single genetic mutations, but the molecular pathways contributing to hypospadias risk are only beginning to be explored [24,25]. Until recently, most studies aiming to identify genes involved in the development of hypospadias have focused on candidate genes, have included small numbers of cases, and have not been replicated [26]. Two recent publications from a large population-based case-control study in California used a candidate gene approach to evaluate associations for 625 relatively common single nucleotide polymorphisms (SNPs) in genes involved in genital tubercle formation, early urethral development, or sex hormone biosynthesis and metabolism [27, 28]. More than 50 SNPs were associated with hypospadias, with some variability by defect severity and by race/ethnic group. As most of the SNPs identified have no known functional consequences, further work is needed to replicate results and elucidate causal variants. A previous genome-wide association study (GWAS) identified a novel link between mild to moderate hypospadias and SNPs in $D G K K$, an X-chromosome locus that encodes diacylglycerol kinase kap$\mathrm{pa}$, which regulates the balance in two signaling lipids [29•]. Subsequent studies, including one in a more racially/ethnically diverse population, confirmed that $D G K K$ SNPs are associated with hypospadias [26, 30]. A recent GWAS identified gene variants at 18 loci associated with hypospadias, which explained nearly $9 \%$ of the variance in liability to the defect [30].

Epigenetic mechanisms are of increasing interest in establishing causal connections between environmental exposures in utero and birth defects, including hypospadias; however, to our knowledge, only two studies have been published that evaluated associations between epigenetic DNA methylation and hypospadias [31, 32]. In the first study, which used a candidate gene approach, greater methylation of the androgen receptor gene was associated with mild hypospadias [31]. The second was an epigenome-wide association study that identified differences in methylation status in hypospadias cases compared with controls at $\mathrm{CpG}$ sites in two genes [32]. However, only 12 cases of hypospadias with heterogeneous phenotypes were included in this study, and results should be confirmed in a larger study population. A caveat of both studies is that preputial tissue collection took place a year or more after birth, and the tissue samples might not have been relevant to hypospadias development. Therefore, methylation patterns that were detected may not reflect those that existed at the time of hypospadias development.

Although hypospadias is generally believed to result from a combination of genetic and environmental factors, to date, there are few data regarding gene-environment interactions and hypospadias risk [33]. To build upon the current literature, future studies may stratify hypospadias by phenotype to reduce potential genetic heterogeneity of the outcome, [29•] increase study size, focus on replicating previous associations and understanding pathways, and evaluate epigenetic and gene-environment interactions.

\section{Risk Factors}

Demographic Factors and Maternal Characteristics

Many demographic and maternal characteristics have been associated with hypospadias with varying degrees of consistency across studies. Specifically, white race-ethnicity has been associated with an increased risk for hypospadias in some but not all studies [16, 34]. These disparate findings could be explained by exposure to environmental risk factors or ascertainment bias that could vary by race/ethnicity [16] Similarly, increasing maternal age has been associated with an increased risk for hypospadias in many but not all studies [16, $35,36]$. For example, Carmichael et al. reported an unadjusted odds ratio of 2.1 (95 \% CI: $1.5-2.8$ ) for moderate to severe hypospadias when comparing women ages 35 and older vs. younger than 25 [36]. In contrast, lower parity has been associated with an increased risk of hypospadias in some but not all studies [37, 38]. In a report from the U.S. National Birth Defects Prevention Study (NBDPS), after adjustment for maternal age, prepregnancy body mass index, and fertility treatment among other factors, the association between parity and moderate to severe hypospadias remained [38]. Considering both age and parity together, another report from the NBDPS demonstrated that women ages 35 and older without a previous live birth had the highest risk for having an infant with moderate to severe hypospadias [36]. With respect to previous pregnancy outcomes, any prior stillbirth has also been linked with hypospadias in at least one study [39].

Maternal prepregnancy obesity (body mass index $\geq 30$ ) has been associated with an approximately 1.3 to 2 -fold increased risk for hypospadias compared to women with normal or overweight prepregnancy body mass index [10, 40-42]. In contrast, a study from Washington State reported no association between maternal obesity and hypospadias, although body mass index was unavailable for nearly $30 \%$ of the pregnancies [43]. No association between maternal smoking or secondhand smoke and risk for moderate to severe hypospadias was observed in the most thorough study on the topic, which evaluated both timing and frequency of smoking [44].

\section{Pregnancy and Birth Characteristics}

Multifetal pregnancies and preeclampsia are associated with an increased risk for hypospadias $[9,10,11 \bullet, 37,39,45,46 \bullet \bullet$, 
47], and infants with hypospadias are more likely to be born preterm, and to be of low birth weight or small for gestational age $[10,11 \bullet \cdot, 37,39,45,46 \bullet \cdot$. These factors tend to be more strongly associated with severe hypospadias than milder forms, although some estimates are imprecise [9, 10, 11••, 15].

Recently, Jensen et al. provided key insights into the relation between birth characteristics and hypospadias using Danish health registers [46••]. The authors demonstrated that low birth weight for gestational age was associated with an increased risk for hypospadias and that the association became stronger with decreasing gestational age at birth. However, short gestation did not greatly increase hypospadias risk among boys with high birth weight for gestational age. Typically, twins have decreased birth weight and gestational age compared with singletons, and some authors have demonstrated that the association between twinning and hypospadias appeared to be protective after accounting for birth weight or gestational age at birth $[39,46 \bullet \cdot$. When considering causal diagrams [48], these findings suggest that hypospadias and fetal growth restriction (manifested by low birth weight) share causes, as opposed to growth restriction leading to hypospadias [46••]. Placental dysfunction and androgen deficiency in early pregnancy have been proposed as shared causes of intrauterine growth restriction and hypospadias [46••, 49, 50]. Specifically, placental dysfunction may lead to inadequate production or transport of human chorionic gonadotropin, or other placenta-derived factors, which fail to stimulate appropriate fetal androgen production necessary for normal urethral closure [49-53] and potentially involved in somatic growth $[54,55]$. Additionally, placental dysfunction may reduce nutrient transfer to the fetus, consequently contributing to restricted growth [56]. However, placental insufficiency after the critical developmental window that results in growth restriction would not cause hypospadias [53]. In Fig. 2, we illustrate relations between pregnancy/birth characteristics and hypospadias, highlighting shared causes of growth restriction and hypospadias.

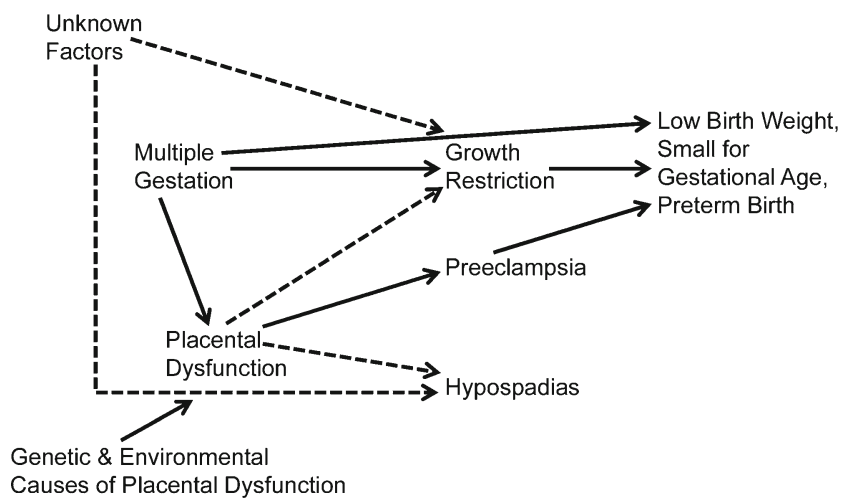

Fig. 2 Conceptual diagram of the relation between pregnancy/birth characteristics and hypospadias. Shared causes of growth restriction and hypospadias are indicated by dashed arrows

\section{Endocrine Disruptors}

Endocrine disruptors are exogenous chemicals that interfere with hormones, and evidence from animal studies indicates that certain endocrine disruptors can cause hypospadias by interfering with androgen and estrogen signaling pathways during sexual differentiation [4]. Recent studies have reported that maternal occupational exposure to endocrine disruptors is associated with an increased risk for hypospadias while paternal occupational exposure associations have tended to be weaker or null [57-59]. These studies assessed occupational exposures based on job title instead of individual workplace exposure levels, which leads to exposure misclassification. Many pesticides are endocrine disruptors, and a metaanalysis reported a modest increased risk for hypospadias associated with maternal (pooled RR: 1.4, $95 \%$ CI: 1.0-1.8) and paternal (pooled RR: 1.2, $95 \%$ CI: 1.0-1.4) occupational exposure to pesticides in general [60]. In a subsequent study from the NBDPS, maternal periconceptional occupational pesticide exposure, based on job description, was not associated with an increased risk for moderate to severe hypospadias [61]. Within pesticide class, no association was observed for fungicides, insecticides, or herbicides. Recently, Carmichael et al. conducted a population-based case-control study in California on residential proximity to a range of specific pesticides [62•]. Few pesticides were associated with hypospadias, none of which had previously been linked to the defect, and results were considered to be hypothesis generating. Although it is biologically plausible that endocrine disruptors contribute to the development of hypospadias, epidemiologic studies have as yet been unable to clearly link specific endocrine disruptors with hypospadias.

\section{Nutritional Factors}

Various nutritional risk factors have been suggested for hypospadias, including vegetarian diet, iron supplements, nutrients related to estrogen metabolism, and low quality diet [41, 63-65]. Carmichael et al. (2012) evaluated these factors, but evidence was not supportive of associations with moderate to severe hypospadias [65]. In contrast, in another study from the same group, maternal intake of certain phytoestrogens, i.e., plant-derived substances with estrogenic properties, and total phytoestrogen intake was negatively associated with moderate to severe hypospadias risk [66]. Folic acid and other nutrients that contribute to one-carbon metabolism have been hypothesized to be associated with a reduced risk for hypospadias given their critical role in developmental processes [67]. Mavrogenis et al. reported that folic acid supplementation early in pregnancy was associated with a decreased risk for hypospadias when supplementation use was ascertained from medical records and an increased risk for hypospadias when only retrospective maternal report was available [68]. 
However, Carmichael et al. (2009) did not observe an association between folic acid supplementation early in pregnancy and moderate to severe hypospadias [67]. Furthermore, dietary intake of other nutrients involved in one-carbon metabolism including choline, methionine, and vitamin B12 was negatively associated with moderate to severe hypospadias risk among women who took folic acid supplements [67]. Recently, Gilboa et al. reported an increased risk for moderate to severe hypospadias in women with the highest periconceptional intake of vitamin $\mathrm{E}$, a lipid soluble antioxidant, from diet and supplements compared with the lowest intake (OR: 1.4, 95 \% CI: 1.1-1.9) [69]. The results were adjusted for several potential confounders including folate intake. This association was unexpected and requires confirmation.

\section{Medications}

The use of several medications during pregnancy has been studied in relation to risk for hypospadias. Studying such associations is challenging because of limited study size due to the relatively low prevalence of pregnancy exposures for most specific medications, the rarity of hypospadias as an outcome, and potential bias due to confounding by underling indication for the medication.

Antiepileptic drugs are among the most well-studied medications with respect to hypospadias. Risk of hypospadias has been reported to be elevated with use of phenobarbital, topiramate, and carbamazepine during pregnancy, although reports are inconsistent and are based on small numbers of cases resulting in imprecise estimates [70-73]. First trimester valproic acid use has been the most consistently associated with hypospadias across various study designs [74-78]. In a case-control study from the EUROCAT database involving 32 exposed cases, Jentink et al. reported a 4.8-fold (95 \% CI: 2.9-8.1) increased odds for exposure to valproic acid in the first trimester among women who had a child with hypospadias compared to women who did not [76]. In another case-control study based on only four exposed cases, Werler et al. reported an odds ratio of 2.4 (95\% CI: 0.6-9.0) for first trimester exposure to valproic acid in women who had a child with hypospadias compared to those who did not [77]. To overcome the imprecise estimate, the authors utilized a Bayesian approach, which incorporated prior knowledge of the magnitude of the association from the literature. This approach resulted in a stronger and more stable odds ratio 3.2 (95\% posterior interval: 1.2-9.0). Furthermore, a recent study from the Medical Birth Registry of Norway reported an odds ratio for hypospadias of 5.7 (95\% CI: 2.1-15.3) when comparing women who used valproic acid monotherapy during pregnancy with women who did not; however, only four women treated with valproic acid had a child with hypospadias [79].
A major concern for observational studies that evaluate the association between medications and adverse outcomes is confounding due to the underlying indication for the medication or the severity of the indication [80]. Van Zutphen et al. explored the impact of antihypertensive use and underlying maternal hypertension on risk for moderate to severe hypospadias [81]. Using a reference group of women without hypertension, the authors reported an odds ratio of $2.1(95 \%$ CI: 1.8-2.5) associated with untreated hypertension and an odds ratio of 1.6 (95\% CI: 1.1-2.3) associated with antihypertensive use early in pregnancy. These results suggest that underlying hypertension plays a role in the development of hypospadias, possibly through reduced placental profusion. Furthermore, the same authors reported an even stronger association with antihypertensive medication initiated only later in pregnancy, after the etiologically relevant period for development of hypospadias (odds ratio (OR): 4.0 (95\% CI: 2.4-6.6) suggesting that the medication could not be the cause. This study illustrates the importance of considering underlying maternal disease and disease severity when studying perinatal medication exposures and risk for hypospadias.

It has been hypothesized that exogenous estrogen and progestin exposures may contribute to the development of hypospadias by interfering with fetal androgen production or action [82, 83]. Results from studies of the association between progestin use and risk for hypospadias have been mixed and may reflect differences in progestin indications and formulations over time [84]. Including pregnancies from 1997-2000, Carmichael et al. reported that progestin use to prevent pregnancy complications, loss or to improve fertility was associated with an increased risk for moderate to severe hypospadias, whereas progestin use for contraception was not [84]. Using Danish register data, including pharmacy prescription information, Nørgaard et al. reported that oral contraceptive use around the first trimester was not associated with an increased risk for hypospadias, even when accounting for exposure misclassification [85]. Diethylstilbestrol (DES), a synthetic estrogen, was banned for use during pregnancy in the United States in 1971 after it was linked to vaginal clear-cell adenocarcinoma among daughters of women who used the drug during pregnancy [86]. Earlier studies suggested that males exposed to DES in utero have an increased risk for genital anomalies [87]. More recently, an intriguing transgenerational effect of DES in the sons of women who had in utero exposure to DES has been explored. Klip et al. first reported in 2002 an association between maternal in utero exposure to DES and hypospadias in the offspring of a cohort of women with fertility problems [88], and follow-up studies lend mixed support [9, 89-91]. Relating medication use in the first generation to an outcome in the third generation is challenging. Methodological limitations include transgenerational confounding by factors such as first generation subfertility and recall bias when maternal in utero exposure is ascertained through self-report [89, 92]. 
Using data from the NBDPS, several other medications have been reported to be associated with moderate to severe hypospadias. These findings included ibuprofen (OR: 1.2, 95\% CI: $1.0-1.3$ ), venlafaxine (OR: 2.4, $95 \%$ CI: $1.0-6.0$ ), proton pump inhibitors (OR: 4.4, $95 \% \mathrm{CI}: 1.2-15.8$ ), and certain fertility treatments including clomiphene citrate (OR: 1.9, 95 \% CI: 1.2-3.0) [93, 94•]. These analyses had limited ability to address confounding by indication, employed multiple comparisons, and are generally considered to be hypothesis generating. Therefore, results should be interpreted in light of the exploratory context and follow-up studies to confirm or refute the findings will be valuable.

\section{Assisted Reproductive Technology (ART)}

ART encompasses fertility treatments in which both sperm and eggs are handled outside the body [95]. In vitro fertilization (IVF) with or without intracytoplasmic sperm injection (ICSI) is the most common type of ART [95]. A study using Western Australian register data from 1994-2002 reported a 2.4-fold (95 \% CI: 1.5-4.0) increased odds for hypospadias associated with ART for singletons based on 17 ART-exposed cases [96]. A report from the NBDPS (1997-2003) demonstrated a 2.1 -fold (95 \% CI: 0.9-5.2) increased odds of moderate to severe hypospadias associated with ART for singleton births [97]. These results were adjusted for maternal age, study center, income, and parity. A case-control study from the Netherlands from 1996-2004 reported a 2.3-fold $(95 \% \mathrm{CI}$ : 0.9-5.8) increased odds of hypospadias associated with ART after adjusting for family history of hypospadias [9]. Using Swedish register data from 2001 to 2007, Kallen et al. reported no association between IVF and hypospadias; there were 45 exposed cases [98]. These findings contradicted a study using Swedish register data between 1982-2001 which reported that IVF was associated with an approximately 2 -fold increased odds for hypospadias [98, 99]. Within specific ART procedure types, some studies have suggested that risk for hypospadias may be highest following ICSI; however, these studies are generally limited by a small number of cases [98-103].

As described above, investigators have reported positive associations between ART and fertility medications, such as
Fig. 3 Conceptual diagram of $\mathbf{a}$ the associations between assisted reproductive technology and hypospadias and fertility medications and hypospadias, $\mathbf{b}$ adding potential common causes of the exposures and hypospadias, and $\mathbf{c}$ adding potential effects of the exposures and the relation of these effects with hypospadias. Asterisk indicates, for example, clomiphene citrate and progestin
A
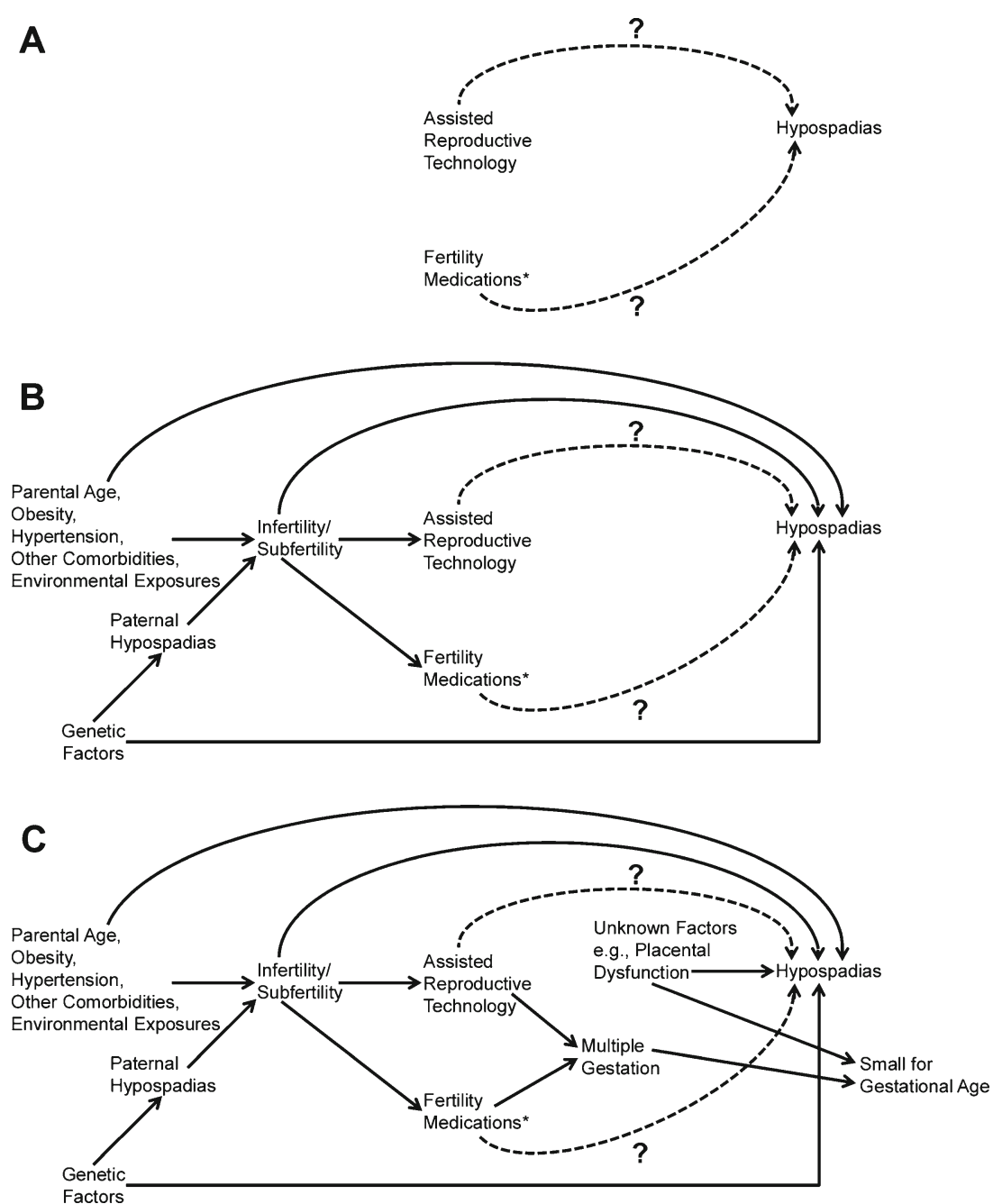
clomiphene citrate and progestin, and hypospadias. However, it is unclear whether these exposures cause hypospadias (Fig. 3a). Confounding, or bias due to common causes of these exposures and hypospadias, is a plausible non-causal alternative explanation for the observed associations. Using a conceptual diagram in Fig. 3b, we illustrate potential common causes of ART, fertility medications, and hypospadias, such as infertility or subfertility, family history of hypospadias, and parental characteristics like comorbidities and environmental exposures. For example, paternal hypospadias may be associated with subfertility [104], and these factors are linked with offspring hypospadias $[9,23]$. The association between ART and hypospadias could be at least partially explained by paternal hypospadias and subfertility. However, no studies have provided convincing evidence that this is the case by accounting for family history of hypospadias and subfertility. Accounting for subfertility is a major methodological challenge for ART studies and could be accomplished in part by accounting for time to pregnancy and type of infertility diagnosis and by making comparisons with subfertile couples that did not undergo ART. Moreover, multiple gestation and small for gestational age are more common among ART pregnancies compared with non-ART pregnancies [95, 105] and may be considered as effects of ART as illustrated in the conceptual diagram in Fig. 3c. To estimate the impact of ART on hypospadias risk, it would be inappropriate to account for these factors in the analysis [106].

When evaluating the association between fertility treatments and hypospadias, investigators must carefully consider which factors to account for in the analysis to reduce bias. Comparison of the risk of hypospadias across fertility treatments, including IVF, ICSI, type of ICSI, ovulation induction, and intrauterine insemination, may provide additional insight into potential mechanisms underlying the development of hypospadias following fertility treatment.

\section{Conclusions}

Hypospadias is one of the most common birth defects in males, and differences in the criteria used to diagnose/treat mild hypospadias as well as variability in reporting standards have likely contributed to temporal variations in the estimates of hypospadias birth prevalence. While hypospadias is highly heritable, there is limited knowledge regarding the specific genetic and epigenetic factors that play a role in its etiology. Risk factors for hypospadias include family history, older maternal age, nulliparity, high prepregnancy body mass index, hypertension or preeclampsia, multiple gestations, low birth weight, and small for gestational age. Of the medications studied, the strongest epidemiologic evidence supports first trimester exposure to valproic acid as a contributor to hypospadias. The impact of ART on hypospadias remains unclear, and epidemiologic studies have as yet been unable to establish conclusive links between specific endocrine disruptors and dietary factors and hypospadias. Although most risk factors are associated with either none or all hypospadias phenotypes, for some factors, the magnitude of the association appears to vary across phenotypes.

Many causes of hypospadias may act through a few shared pathways. For example, placental dysfunction may contribute to the development of hypospadias and also cause growth restriction, and upstream causes of placental dysfunction would be implicated as causes of hypospadias.

There are a number of challenges of evaluating potential causes of hypospadias through observational research. First, attaining an adequate number of hypospadias cases with accurate phenotype information is necessary for precise estimations of the association. Phenotype-specific causes could be overlooked if all hypospadias cases are grouped together. Second, accurate ascertainment of specific exposures during the etiologically relevant window that does not depend on hypospadias status is necessary to avoid bias. Finally, to eliminate confounding as a non-causal explanation of an association, accounting for underlying common causes of the exposure of interest and hypospadias is necessary. In addition to phenotype-specific analysis, valuable directions for future hypospadias research include confirmation of suggested associations, including genetic variants, epigenetic marks, and specific medications, further exploration of paternal exposures, investigation of specific endocrine disruptors using rigorous exposure assessments, and the evaluation of subfertility and different fertility treatments on the risk for hypospadias.

\section{Compliance with Ethics Guidelines}

Conflict of Interest K Palmsten and CD Chambers both declare no conflicts of interest.

Human and Animal Rights and Informed Consent This article does not contain any studies with human or animal subjects performed by any of the authors.

\section{References}

Papers of particular interest, published recently, have been highlighted as:

- Of importance

•. Of major of importance

1. Baskin LS, Erol A, Jegatheesan P, Li Y, Liu W, Cunha GR. Urethral seam formation and hypospadias. Cell Tissue Res. 2001;305(3):379-87.

2. Welsh M, Saunders PT, Fisken M, et al. Identification in rats of a programming window for reproductive tract masculinization, 
disruption of which leads to hypospadias and cryptorchidism. J Clin Invest. 2008;118(4):1479-90.

3. Baskin LS, Himes K, Colborn T. Hypospadias and endocrine disruption: is there a connection? Environ Health Perspect. 2001;109(11):1175-83.

4. Carmichael SL, Shaw GM, Lammer EJ. Environmental and genetic contributors to hypospadias: a review of the epidemiologic evidence. Birth Defects Res A Clin Mol Teratol. 2012;94(7):499_ 510.

5. Soderhall C, Korberg IB, Thai HT, et al. Fine mapping analysis confirms and strengthens linkage of four chromosomal regions in familial hypospadias. Eur J Hum Genet. 2014.

6. Dolk H, Vrijheid M, Scott JE, et al. Toward the effective surveillance of hypospadias. Environ Health Perspect. 2004;112(3):398402.

7. Prat D, Natasha A, Polak A, et al. Surgical outcome of different types of primary hypospadias repair during three decades in a single center. Urology. 2012;79(6):1350-3.

8. Spinoit AF, Poelaert F, Groen LA, Van Laecke E, Hoebeke P. Hypospadias repair at a tertiary care center: long-term followup is mandatory to determine the real complication rate. J Urol. 2013;189(6):2276-81.

9. Brouwers MM, van der Zanden LF, de Gier RP, et al. Hypospadias: risk factor patterns and different phenotypes. BJU Int. 2010;105(2):254-62.

10. van Rooij IA, van der Zanden LF, Brouwers MM, Knoers NV, Feitz WF, Roeleveld N. Risk factors for different phenotypes of hypospadias: results from a Dutch case-control study. BJU Int. 2013;112(1):121-8.

11.• Woud SG, van Rooij IA, van Gelder MM, et al. Differences in risk factors for second and third degree hypospadias in the national birth defects prevention study. Birth Defects Res A Clin Mol Teratol. 2014;100(9):703-11. A population-based case-control study that evaluated the associations between many risk factors and moderate and severe hypospadias, separately. Family history was more strongly associated with moderate hypospadias than severe hypospadias. Risk factors related to placental dysfunction were more strongly associated with severe hypospadias than moderate hypospadias.

12. Paulozzi LJ, Erickson JD, Jackson RJ. Hypospadias trends in two US surveillance systems. Pediatrics. 1997;100(5):831-4.

13. Li Y, Mao M, Dai L, et al. Time trends and geographic variations in the prevalence of hypospadias in China. Birth Defects Res A Clin Mol Teratol. 2012;94(1):36-41.

14. Loane M, Dolk H, Kelly A, Teljeur C, Greenlees R, Densem J. Paper 4: EUROCAT statistical monitoring: identification and investigation of ten year trends of congenital anomalies in Europe. Birth Defects Res A Clin Mol Teratol. 2011;91 Suppl 1:S31-43.

15. Carmichael SL, Shaw GM, Nelson V, Selvin S, Torfs CP, Curry CJ. Hypospadias in California: trends and descriptive epidemiology. Epidemiology. 2003;14(6):701-6.

16. Porter MP, Faizan MK, Grady RW, Mueller BA. Hypospadias in Washington State: maternal risk factors and prevalence trends. Pediatrics. 2005;115(4):e495-9.

17. Fisch H, Lambert SM, Hensle TW, Hyun G. Hypospadias rates in New York State are not increasing. J Urol. 2009;181(5):2291-4.

18. Fisch H, Hyun G, Hensle TW. Rising hypospadias rates: disproving a myth. J Pediatr Urol. 2010;6(1):37-9.

19. Aho M, Koivisto AM, Tammela TL, Auvinen A. Is the incidence of hypospadias increasing? Analysis of Finnish hospital discharge data 1970-1994. Environ Health Perspect. 2000;108(5):463-5.

20. Toppari J, Kaleva M, Virtanen HE. Trends in the incidence of cryptorchidism and hypospadias, and methodological limitations of registry-based data. Hum Reprod Update. 2001;7(3):282-6.

21. Paulozzi LJ. International trends in rates of hypospadias and cryptorchidism. Environ Health Perspect. 1999;107(4):297-302.
22. EUROCAT. Minor Anomalies for Exclusion. http://www.eurocatnetwork.eu/aboutus/datacollection/guidelinesforregistration/ previouscodingguides/instructionmanuals. Accessed August 21, 2014.

23. Schnack TH, Zdravkovic S, Myrup C, et al. Familial aggregation of hypospadias: a cohort study. Am J Epidemiol. 2008;167(3): 251-6.

24. Fredell L, Iselius L, Collins A, et al. Complex segregation analysis of hypospadias. Hum Genet. 2002;111(3):231-4.

25. van der Zanden LF, van Rooij IA, Feitz WF, et al. Genetics of hypospadias: are single-nucleotide polymorphisms in SRD5A2, ESR1, ESR2, and ATF3 really associated with the malformation? J Clin Endocrinol Metab. 2010;95(5):2384-90.

26. Carmichael SL, Mohammed N, Ma C, et al. Diacylglycerol kinase $\mathrm{K}$ variants impact hypospadias in a California study population. J Urol. 2013;189(1):305-11.

27. Carmichael SL, Ma C, Choudhry S, Lammer EJ, Witte JS, Shaw GM. Hypospadias and genes related to genital tubercle and early urethral development. J Urol. 2013;190(5):1884-92.

28. Carmichael SL, Witte JS, Ma C, Lammer EJ, Shaw GM. Hypospadias and variants in genes related to sex hormone biosynthesis and metabolism. Andrology. 2014;2(1):130-7.

29. van der Zanden LF, van Rooij IA, Feitz WF, et al. Common variants in DGKK are strongly associated with risk of hypospadias. Nat Genet. 2011;43(1):48-50. The first genome wide association study of hypospadias cases. The study, conducted among individuals with European decent, identified common variants in the DGKK gene associated with mild to moderate hypospadias. This gene had not previously been linked with hypospadias.

30. Geller F, Feenstra B, Carstensen L, et al. Genome-wide association analyses identify variants in developmental genes associated with hypospadias. Nat Genet. 2014;46(9):957-63.

31. Vottero A, Minari R, Viani I, et al. Evidence for epigenetic abnormalities of the androgen receptor gene in foreskin from children with hypospadias. J Clin Endocrinol Metab. 2011;96(12):E1953-62.

32. Choudhry S, Deshpande A, Qiao L, Beckman K, Sen S, Baskin LS. Genome-wide DNA methylation profiling of $\mathrm{CpG}$ islands in hypospadias. J Urol. 2012;188(4 Suppl):1450-5.

33. van der Zanden LF, Galesloot TE, Feitz WF, et al. Exploration of gene-environment interactions, maternal effects and parent of origin effects in the etiology of hypospadias. J Urol. 2012;188(6):2354-60.

34. Yang J, Carmichael SL, Kaidarova Z, Shaw GM. Risks of selected congenital malformations among offspring of mixed race-ethnicity. Birth Defects Res A Clin Mol Teratol. 2004;70(10):820-4.

35. Fisch H, Golden RJ, Libersen GL, et al. Maternal age as a risk factor for hypospadias. J Urol. 2001;165(3):934-6.

36. Carmichael SL, Shaw GM, Laurent C, Olney RS, Lammer EJ. Maternal reproductive and demographic characteristics as risk factors for hypospadias. Paediatr Perinat Epidemiol. 2007;21(3): $210-8$.

37. Akre O, Lipworth L, Cnattingius S, Sparen P, Ekbom A. Risk factor patterns for cryptorchidism and hypospadias. Epidemiology. 1999;10(4):364-9.

38. Duong HT, Hoyt AT, Carmichael SL, et al. Is maternal parity an independent risk factor for birth defects? Birth Defects Res A Clin Mol Teratol. 2012;94(4):230-6.

39. Weidner IS, Moller H, Jensen TK, Skakkebaek NE. Risk factors for cryptorchidism and hypospadias. J Urol. 1999;161(5):1606-9.

40. Waller DK, Shaw GM, Rasmussen SA, et al. Prepregnancy obesity as a risk factor for structural birth defects. Arch Pediatr Adolesc Med. 2007;161(8):745-50.

41. Akre O, Boyd HA, Ahlgren M, et al. Maternal and gestational risk factors for hypospadias. Environ Health Perspect. 2008;116(8): 1071-6. 
42. Blomberg MI, Kallen B. Maternal obesity and morbid obesity: the risk for birth defects in the offspring. Birth Defects Res A Clin Mol Teratol. 2010;88(1):35-40.

43. Adams SV, Hastert TA, Huang Y, Starr JR. No association between maternal pre-pregnancy obesity and risk of hypospadias or cryptorchidism in male newborns. Birth Defects Res A Clin Mol Teratol. 2011;91(4):241-8.

44. Carmichael SL, Shaw GM, Laurent C, Lammer EJ, Olney RS. National Birth Defects Prevention Study. Hypospadias and maternal exposures to cigarette smoke. Paediatr Perinat Epidemiol. 2005;19(6):406-12.

45. Aschim EL, Haugen TB, Tretli S, Daltveit AK, Grotmol T. Risk factors for hypospadias in Norwegian boys - association with testicular dysgenesis syndrome? Int J Androl. 2004;27(4):213-21.

46.• Jensen MS, Wilcox AJ, Olsen J, et al. Cryptorchidism and hypospadias in a cohort of 934,538 Danish boys: the role of birth weight, gestational age, body dimensions, and fetal growth. Am J Epidemiol. 2012;175(9):917-25. A study that used Danish health registry data to investigate the relation between infant characteristics and hypospadias and cryptorchidism, separately. Data suggest that fetal growth restriction shares common causes with hypospadias and cryptorchidism.

47. Rider RA, Stevenson DA, Rinsky JE, Feldkamp ML. Association of twinning and maternal age with major structural birth defects in Utah, 1999 to 2008. Birth Defects Res A Clin Mol Teratol. 2013;97(8):554-63.

48. Hernandez-Diaz S, Schisterman EF, Hernan MA. The birth weight "paradox" uncovered? Am J Epidemiol. 2006;164(11):1115-20.

49. Moller H, Weidner IS. Epidemiology of cryptorchidism and hypospadias. Epidemiology. 1999;10(4):352-4.

50. Fujimoto T, Suwa T, Kabe K, Adachi T, Nakabayashi M, Amamiya T. Placental insufficiency in early gestation is associated with hypospadias. J Pediatr Surg. 2008;43(2):358-61.

51. Kiely EA, Chapman RS, Bajoria SK, Hollyer JS, Hurley R. Maternal serum human chorionic gonadotrophin during early pregnancy resulting in boys with hypospadias or cryptorchidism. Br J Urol. 1995;76(3):389-92.

52. Brouwers MM, Feitz WF, Roelofs LA, Kiemeney LA, de Gier RP, Roeleveld N. Risk factors for hypospadias. Eur J Pediatr. 2007;166(7):671-8.

53. Chen MJ, Macias CG, Gunn SK, et al. Intrauterine growth restriction and hypospadias: is there a connection? Int $\mathrm{J}$ Pediatr Endocrinol. 2014;2014(1):20.

54. Hughes IA, Northstone K, Golding J, Team AS. Reduced birth weight in boys with hypospadias: an index of androgen dysfunction? Arch Dis Child Fetal Neonatal Ed. 2002;87(2):F150-1.

55. Scaramuzzo RT, Boldrini A, Bertelloni S, Parrini D, Serino L, Ghirri P. Low testosterone levels in pre-term newborns born small for gestational age. J Endocrinol Invest. 2010;33(4):215-7.

56. Miller J, Turan S, Baschat AA. Fetal growth restriction. Semin Perinatol. 2008;32(4):274-80.

57. Giordano F, Abballe A, De Felip E, et al. Maternal exposures to endocrine disrupting chemicals and hypospadias in offspring. Birth Defects Res A Clin Mol Teratol. 2010;88(4):241-50.

58. Nassar N, Abeywardana P, Barker A, Bower C. Parental occupational exposure to potential endocrine disrupting chemicals and risk of hypospadias in infants. Occup Environ Med. 2010;67(9):585-9.

59. Morales-Suarez-Varela MM, Toft GV, Jensen MS, et al. Parental occupational exposure to endocrine disrupting chemicals and male genital malformations: a study in the Danish National Birth Cohort study. Environ Health. 2011;10(1):3.

60. Rocheleau CM, Romitti PA, Dennis LK. Pesticides and hypospadias: a meta-analysis. J Pediatr Urol. 2009;5(1):17-24.

61. Rocheleau CM, Romitti PA, Sanderson WT, et al. Maternal occupational pesticide exposure and risk of hypospadias in the
National Birth Defects Prevention Study. Birth Defects Res A Clin Mol Teratol. 2011;91(11):927-36.

62. Carmichael SL, Yang W, Roberts EM, et al. Hypospadias and residential proximity to pesticide applications. Pediatrics. 2013;132(5):e1216-26. A population based case-control study in California that evaluated the association between a wide range of pesticide applications at the residential level and risk for hypospadias. Most pesticide exposures were not associated with hypospadias, however, the positive associations should be evaluated in future studies.

63. North K, Golding J. A maternal vegetarian diet in pregnancy is associated with hypospadias. The ALSPAC Study Team. Avon Longitudinal Study of Pregnancy and Childhood. BJU Int. 2000;85(1):107-13.

64. de Kort CA, Nieuwenhuijsen MJ, Mendez MA. Relationship between maternal dietary patterns and hypospadias. Paediatr Perinat Epidemiol. 2011;25(3):255-64

65. Carmichael SL, Ma C, Feldkamp ML, et al. Nutritional factors and hypospadias risks. Paediatr Perinat Epidemiol. 2012;26(4):353-60.

66. Carmichael SL, Cogswell ME, Ma C, et al. Hypospadias and maternal intake of phytoestrogens. Am J Epidemiol. 2013;178(3):434-40.

67. Carmichael SL, Yang W, Correa A, Olney RS, Shaw GM. National Birth Defects Prevention Study. Hypospadias and intake of nutrients related to one-carbon metabolism. J Urol. 2009;181(1):315-21.

68. Mavrogenis S, Urban R, Czeizel AE, Acs N. Possible preventive effect of high doses of folic acid for isolated hypospadias: a national population-based case-control study. Am J Med Genet A. 2014;164(12):3108-14.

69. Gilboa SM, Lee KA, Cogswell ME, et al. Maternal intake of vitamin $\mathrm{E}$ and birth defects, national birth defects prevention study, 1997 to 2005. Birth Defects Res A Clin Mol Teratol. 2014;100(9):647-57.

70. Arpino C, Brescianini S, Robert E, et al. Teratogenic effects of antiepileptic drugs: use of an International Database on Malformations and Drug Exposure (MADRE). Epilepsia. 2000;41(11):1436-43.

71. Hunt S, Russell A, Smithson WH, et al. Topiramate in pregnancy: preliminary experience from the UK Epilepsy and Pregnancy Register. Neurology. 2008;71(4):272-6.

72. Vajda FJ, O'Brien TJ, Graham J, Lander CM, Eadie MJ. Associations between particular types of fetal malformation and antiepileptic drug exposure in utero. Acta Neurol Scand. 2013;128(4):228-34.

73. Jentink J, Dolk H, Loane MA, et al. Intrauterine exposure to carbamazepine and specific congenital malformations: systematic review and case-control study. BMJ. 2010;341:c6581.

74. Samren EB, van Duijn CM, Christiaens GC, Hofman A, Lindhout D. Antiepileptic drug regimens and major congenital abnormalities in the offspring. Ann Neurol. 1999;46(5):739-46.

75. Rodriguez-Pinilla E, Mejias C, Prieto-Merino D, Fernandez P, Martinez-Frias ML, Group EW. Risk of hypospadias in newborn infants exposed to valproic acid during the first trimester of pregnancy: a case-control study in Spain. Drug Saf. 2008;31(6):537-43.

76. Jentink J, Loane MA, Dolk H, et al. Valproic acid monotherapy in pregnancy and major congenital malformations. N Engl J Med. 2010;362(23):2185-93.

77. Werler MM, Ahrens KA, Bosco JL, et al. Use of antiepileptic medications in pregnancy in relation to risks of birth defects. Ann Epidemiol. 2011;21(11):842-50.

78. Hernandez-Diaz S, Smith CR, Shen A, et al. Comparative safety of antiepileptic drugs during pregnancy. Neurology. 2012;78(21): 1692-9.

79. Veiby G, Daltveit AK, Engelsen BA, Gilhus NE. Fetal growth restriction and birth defects with newer and older antiepileptic drugs during pregnancy. J Neurol. 2014;261(3):579-88. 
80. Schneeweiss S, Avorn J. A review of uses of health care utilization databases for epidemiologic research on therapeutics. J Clin Epidemiol. 2005;58(4):323-37.

81. Van Zutphen AR, Werler MM, Browne MM, et al. Maternal hypertension, medication use, and hypospadias in the National Birth Defects Prevention Study. Obstet Gynecol. 2014;123(2 Pt 1):309-17.

82. Sharpe RM, Skakkebaek NE. Are oestrogens involved in falling sperm counts and disorders of the male reproductive tract? Lancet. 1993;341(8857):1392-5.

83. Aarskog D. Maternal progestins as a possible cause of hypospadias. N Engl J Med. 1979;300(2):75-8.

84. Carmichael SL, Shaw GM, Laurent C, Croughan MS, Olney RS, Lammer EJ. Maternal progestin intake and risk of hypospadias. Arch Pediatr Adolesc Med. 2005;159(10):957-62.

85. Norgaard M, Wogelius P, Pedersen L, Rothman KJ, Sorensen HT. Maternal use of oral contraceptives during early pregnancy and risk of hypospadias in male offspring. Urology. 2009;74(3):583-7.

86. Giusti RM, Iwamoto K, Hatch EE. Diethylstilbestrol revisited: a review of the long-term health effects. Ann Intern Med. 1995;122(10):778-88.

87. Wilcox AJ, Baird DD, Weinberg CR, Hornsby PP, Herbst AL. Fertility in men exposed prenatally to diethylstilbestrol. N Engl J Med. 1995;332(21):1411-6.

88. Klip H, Verloop J, van Gool JD, Koster ME, Burger CW, van Leeuwen FE. Hypospadias in sons of women exposed to diethylstilbestrol in utero: a cohort study. Lancet. 2002;359(9312):1102-7.

89. Palmer JR, Wise LA, Robboy SJ, et al. Hypospadias in sons of women exposed to diethylstilbestrol in utero. Epidemiology. 2005;16(4):583-6.

90. Brouwers MM, Feitz WF, Roelofs LA, Kiemeney LA, de Gier RP, Roeleveld N. Hypospadias: a transgenerational effect of diethylstilbestrol? Hum Reprod. 2006;21(3):666-9.

91. Kalfa N, Paris F, Soyer-Gobillard MO, Daures JP, Sultan C. Prevalence of hypospadias in grandsons of women exposed to diethylstilbestrol during pregnancy: a multigenerational national cohort study. Fertil Steril. 2011;95(8):2574-7.

92. Hernandez-Diaz S. Iatrogenic legacy from diethylstilbestrol exposure. Lancet. 2002;359(9312):1081-2.

93. Anderka M, Mitchell AA, Louik C, Werler MM, Hernandez-Diaz $\mathrm{S}$, Rasmussen SA. Medications used to treat nausea and vomiting of pregnancy and the risk of selected birth defects. Birth Defects Res A Clin Mol Teratol. 2012;94(1):22-30.

94. Lind JN, Tinker SC, Broussard CS, et al. Maternal medication and herbal use and risk for hypospadias: data from the National Birth Defects Prevention Study, 1997-2007. Pharmacoepidemiol Drug Saf. 2013;22(7):783-93. A hypothesis generating populationbased case-control study that evaluated the association between commonly used medications during pregnancy and risk for moderate to severe hypospadias. Most medications were not associated with hypospadias, however, the positive associations should be evaluated in future studies.

95. Centers for Disease Control and Prevention. 2010 Assisted Reproductive Technology Report-Fertility Clinic Success Rates. http://www.cdc.gov/art/ART2010/download.htm Accessed August 22, 2014.

96. Hansen M, Kurinczuk JJ, de Klerk N, Burton P, Bower C. Assisted reproductive technology and major birth defects in Western Australia. Obstet Gynecol. 2012;120(4):852-63.

97. Reefhuis J, Honein MA, Schieve LA, et al. Assisted reproductive technology and major structural birth defects in the United States. Hum Reprod. 2009;24(2):360-6.

98. Kallen B, Finnstrom O, Lindam A, Nilsson E, Nygren KG, Otterblad PO. Congenital malformations in infants born after in vitro fertilization in Sweden. Birth Defects Res A Clin Mol Teratol. 2010;88(3):137-43.

99. Kallen B, Finnstrom O, Nygren KG, Olausson PO. In vitro fertilization (IVF) in Sweden: risk for congenital malformations after different IVF methods. Birth Defects Res A Clin Mol Teratol. 2005;73(3):162-9.

100. Funke S, Flach E, Kiss I, et al. Male reproductive tract abnormalities: more common after assisted reproduction? Early Hum Dev. 2010;86(9):547-50.

101. Fedder J, Loft A, Parner ET, Rasmussen S, Pinborg A. Neonatal outcome and congenital malformations in children born after ICSI with testicular or epididymal sperm: a controlled national cohort study. Hum Reprod. 2013;28(1):230-40.

102. Bonduelle M, Liebaers I, Deketelaere V, et al. Neonatal data on a cohort of 2889 infants born after ICSI (1991-1999) and of 2995 infants born after IVF (1983-1999). Hum Reprod. 2002;17(3): 671-94.

103. Pinborg A, Loft A, Nyboe AA. Neonatal outcome in a Danish national cohort of 8602 children born after in vitro fertilization or intracytoplasmic sperm injection: the role of twin pregnancy. Acta Obstet Gynecol Scand. 2004;83(11):1071-8.

104. Asklund C, Jensen TK, Main KM, Sobotka T, Skakkebaek NE, Jorgensen N. Semen quality, reproductive hormones and fertility of men operated for hypospadias. Int J Androl. 2010;33(1):80-7.

105. Pandey S, Shetty A, Hamilton M, Bhattacharya S, Maheshwari A. Obstetric and perinatal outcomes in singleton pregnancies resulting from IVF/ICSI: a systematic review and meta-analysis. Hum Reprod Update. 2012;18(5):485-503.

106. Hernan MA, Hernandez-Diaz S, Werler MM, Mitchell AA Causal knowledge as a prerequisite for confounding evaluation: an application to birth defects epidemiology. Am J Epidemiol. 2002;155(2):176-84.

107. Pierik FH, Burdorf A, Nijman JM, de Muinck Keizer-Schrama SM, Juttmann RE, Weber RF. A high hypospadias rate in The Netherlands. Hum Reprod. 2002;17(4):1112-5. 